\title{
SOCIEDADE DE INFORMAÇÃO, AMBIENTE VIRTUAL E CÓDIGO DE DEFESA DO CONSUMIDOR: POSSIBILIDADE DE RESPONSABILIZAÇÃO DAS REDES SOCIAIS EM RAZÃO DE DANOS CAUSADOS AOS USUÁRIOS ATRAVÉS DA ÓTICA CONSUMERISTA
}

\author{
INFORMATION SOCIETY, VIRTUAL ENVIRONMENT AND CODE OF \\ CONSUMER PROTECTION: ACCOUNTABILITY OF THE POSSIBILITY OF \\ NETWORKS BY REASON OF DAMAGE TO USERS THROUGH OPTCIAL \\ CONSUMERIST
}

Fernando GabBi Polli Bacharel em Ciência Jurídicas e Sociais pela Universidade Federal de Santa Maria. Especializando-se em Direito Processual Civil pelo Instituto Brasileiro de Direito Processual.

MAYUMI IGUCHI LUFT Bacharel em Direito pelo Centro Universitário Franciscano.

\section{RESUMO}

O presente artigo tem por objetivo analisar a natureza jurídica da relação estabelecida entre os sites provedores de espaços sociais na rede mundial de consumidores (redes sociais) e os usuários dos serviços ofertados, tendo por base a possível relação de consumo existente. Alicerçado nas conclusões quanto à natureza desta relação, o trabalho passa ao estudo da possibilidade de tutela dos usuários dos serviços oferecidos pelos sites de relacionamento, com fundamento na legislação consumerista pátria.

Palavras-chave: direito consumidor; rede social; responsabilidade civil; socidedade de informação.

\begin{abstract}
This article aims to analyze the legal nature of the relationship between providers of social spaces sites on the world wide consumers (social networks) and users of services offered, considering the possible relationship existing consumption. Based on the conclusions regarding the nature of this relationship, the work is to study the possibility of protection of users of the services offered by social networking sites on the basis of legislation consumerist nation.
\end{abstract}

Keywords: consumer rights; social network; liability; information society.

\section{SUMÁRIO}

INTRODUÇÃO; 1 SOCIEDADE DE INFORMAÇÃO E REDES SOCIAIS: UMA NOVA ORGANIZAÇÃO DA SOCIEDADE; 1.1 Redes Sociais: fenômeno sem limites; 1.2. Informações de navegação e a barganha cibernética; 2 PRIVACIDADE DISSIMULADA; 3 APLICABILIDADE DO CÓDIGO DE DEFESA DO CONSUMIDOR; 4 POSSIBILIDADE DE RESPONSABILIZAÇÃO DAS REDES SOCIAIS PELO USO INDEVIDO DE INFORMAÇÕES; 5 JURISPRUDÊNCIA PÁTRIA; CONCLUSÃO; REFERÊNCIAS. 
ISSN 1981-3694

(DOI) $10.5902 / 198136947425$

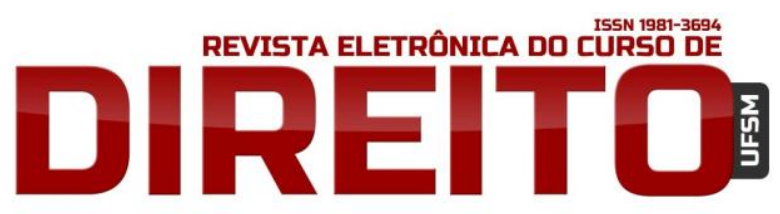

SOCIEDADE DE INFORMAÇÃO, AMBIENTE VIRTUAL E CÓDIGO DE DEFESA DO CONSUMIDOR: POSSIBILIDADE DE RESPONSABILIZAÇÃO DAS REDES SOCIAIS EM RAZÃO DE DANOS CAUSADOS AOS USUÁRIOS ATRAVÉS DA ÓTICA CONSUMERISTA

\section{INTRODUÇÃO}

O homem, como ser social que é, precisa fazer parte de um grupo social ou, ao menos, estar em contato com as pessoas. Essa necessidade, hoje, pode ser suprida - ou amenizada - com o uso das redes sociais ou sites de relacionamento. No decorrer de muitos anos a tecnologia foi desenvolvida em prol da comunicação, sendo que as redes sociais existem, pelo menos, desde 1995, tendo ocorrido um nítido crescimento a partir dos anos $2000^{1}$.

Atualmente, a internet não apenas permite que as pessoas entrem em contato umas com as outras, como também facilita o acesso à informação, cria novas formas de estudo e trabalho, et cetera.

Verifica-se que as invenções e o rápido avanço tecnológico estão modificando a compreensão do mundo, causando, dessa forma, uma necessária readaptação do modo de vida do homem. Faz parte da vida cotidiana da grande maioria dos usuários da rede mundial de computadores a filiação e utilização de ambientes sociais cibernéticos. A estes ambientes de socialização virtual, sites de relacionamentos, damos o nome de redes sociais.

Não há dúvida que o meio de relacionamento entre os usuários de internet tem se expandido de forma rápida e muitas vezes descontrolada. O regramento legal para comportamentos de seus usuários não se produz na mesma velocidade em que surgem estas novas tecnologias, de modo que muitas das vezes temos que buscar em diplomas legais já existentes, alternativas para regular minimamente a sua utilização e os limites da mesma. Temos que encontrar a melhor alternativa dentro da "moldura" existente, como ensina Hans Kelsen ${ }^{2}$.

Frente a esta realidade, chama atenção à necessidade de tutela dos usuários das redes sociais frente aos riscos da utilização dos sites de relacionamento, principalmente no que tange a sua superexposição com relação a dados pessoais e comportamento na rede. Entendemos que não pode o usuário ficar desprotegido, vulnerável, frente à utilização de seus dados pelas redes sociais, devendo estas ser responsabilizadas pelos riscos da atividade explorada, principalmente no que diz respeito a possíveis danos que venham a ser experimentados por seus "clientes".

\footnotetext{
${ }_{1}^{1}$ Disponível em: < http://www.techtudo.com.br/artigos/noticia/2012/07/historia-das-redes-sociais.html> Acesso em 04 dez. 2012.

2 KELSEN, Hans. Teoria Pura do Direito. 6a . ed. São Paulo: Martins Fontes, 2000.
} 
ISSN 1981-3694

(DOI) $10.5902 / 198136947425$

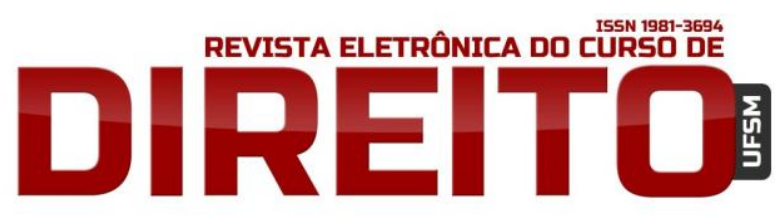

SOCIEDADE DE INFORMAÇÃO, AMBIENTE VIRTUAL E CÓDIGO DE DEFESA DO CONSUMIDOR: POSSIBILIDADE DE RESPONSABILIZAÇÃO DAS REDES SOCIAIS EM RAZÃO DE DANOS CAUSADOS AOS USUÁRIOS ATRAVÉS DA ÓTICA CONSUMERISTA

FERNANDO GABBI POLLI MAYUMI IGUCHI LUFT

O objetivo do trabalho é verificar a possibilidade de responsabilização de empresas em face da utilização de dados de usuários das redes sociais, a partir do estudo da atual configuração dos sites de relacionamento.

Para desenvolver o presente trabalho, foi utilizado o método monográfico. Inicialmente, foi realizada a observação dos funcionamentos dos principais sitios de relacionamento, principalmente no que concerne a relação entre site e usuário. Para tanto, utilizar-se-á o estudo de caso de alguns dos sites de relacionamentos mais utilizados - Facebook, Orkut e Twiter.

A escolha dos sites se dá em razão do seu grande alcance entre os usuários, bem como por se tratarem das duas maiores empresas de internet - Microsoft e Google. Nesta etapa, pretendeu compreender como se dá a relação estudada, bem como o modo através do qual são coletados os dados dos usuários e sua consequente utilização pelas administradoras dos sítios eletrônicos.

Os dados foram coletados através da observação dos sites e suas propagandas. Tais observações foram retiradas dos fatos vivenciados pelos pesquisadores. As informações levantadas e registradas de acordo com a sua relevância.

Em um segundo momento, foi realizado levantamento doutrinário pertinente, através de pesquisa bibliográfica de trabalhos que abordem o tema estudado. Também se buscou efetuar levantamento pertinente no ordenamento jurídico brasileiro, legislações que tratem do tema, ou de relações análogas.

Por fim, foi realizada a confrontação das observações realizadas com a doutrina e legislação levantada, de modo a retirar as conclusões quanto a possível violação de direitos básicos do usuário, sendo, ao final, propostas soluções legais que mais se adéquem as relações jurídicas caracterizadas.

Utilizar-se-á o método dedutivo, utilizando-se como ponto de partida os princípios constitucionais que tutelam a intimidade e o direito à autodeterminação - livre navegação na internet - bem como a análise da prática realizada pelas empresas administradoras de sites de relacionamento quanto à utilização de dados pessoais e registros de navegação na Internet. A esse método se unirá a técnica de pesquisa documental, consultando-se autores nacionais e estrangeiros que estudam o tema.

Assim, o presente artigo, através de uma pesquisa bibliográfica, fazendo uso prioritariamente do método dedutivo, visa ensaiar uma resposta à seguinte questão: é possível a 
ISSN 1981-3694

(DOI) $10.5902 / 198136947425$

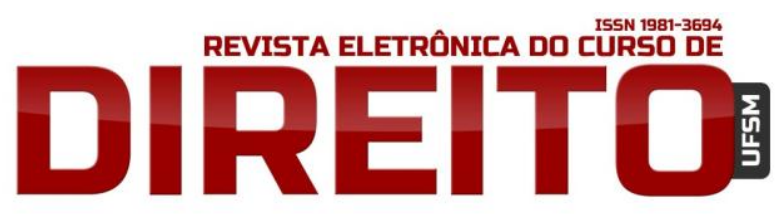

SOCIEDADE DE INFORMAÇÃO, AMBIENTE VIRTUAL E CÓDIGO DE DEFESA DO CONSUMIDOR: POSSIBILIDADE DE RESPONSABILIZAÇÃO DAS REDES SOCIAIS EM RAZÃO DE DANOS CAUSADOS AOS USUÁRIOS ATRAVÉS DA ÓTICA CONSUMERISTA

FERNANDO GABBI POLLI MAYUMI IGUCHI LUFT

responsabilização das redes sociais por eventuais danos e prejuízos experimentados por seus usuários em razão do serviço prestado?

\section{SOCIEDADE DE INFORMAÇÃO E REDES SOCIAIS: UMA NOVA ORGANIZAÇÃO DA SOCIEDADE}

Sociedade de informação “é um estágio de desenvolvimento social caracterizado pela capacidade de seus membros (cidadãos, empresas e administração pública) de obter e compartilhar qualquer informação, instantaneamente, de qualquer lugar e da maneira mais adequada". Do mesmo modo a sociedade da informação é a sociedade contemporânea da inter-relação do ser humano ao ser humano, sendo a máquina e a internet apenas um meio tecnológico dessas novas comunicações, troca de bens e serviços e direitos envolvidos entre as partes pelos meios eletrônicos. É nesse aspecto que interessa para a ciência jurídica, apesar de ambas as idéias serem o conjunto dessa nova realidade ${ }^{4}$.

A evolução da sociedade não se deu apenas com relação aos meios de produção. Para saciar a necessidade de informações, o homem desenvolveu modos cada vez mais rápidos e eficientes equipamentos de difusão de notícias, a fim de que um maior número de pessoas tome conhecimento dos fatos do mundo.

A sociedade, considerada como uma aldeia global composta por organizações e pessoas, é dotada de mecanismos próprios que possibilitam o livre acesso ao conhecimento e comunicação. Este é o grande marco da sociedade atual: a possibilidade de acesso ao conhecimento e à informação, diferentemente do que ocorria antigamente, quando a busca maior era em relação a bens e serviços.

A nova organização da sociedade se dá com base nos terminais, redes e servidores. Cada um destes itens leva a informação até o seu destinatário final: o terminal está relacionado com o equipamento que permite o acesso à informação; servidor é o equipamento que armazena a informação, e a rede é a ligação terminal-servidor. Este é o sistema que viabiliza o acesso e a

\footnotetext{
${ }^{3}$ A sociedade de informação no Brasil - Publicação realizada pelo Grupo Telefônica no Brasil; $1^{\text {a }}$ ed. Dez./2002.

${ }^{4}$ Rodrigo da Cunha Lima Freire, 0 processo civil na sociedade da informação: estudo de um caso. Revista do Instituto dos Advogados de São Paulo, n. 17, São Paulo: Revista dos Tribunais, 2006, p. 247.
} 
ISSN 1981-3694

(DOI) $10.5902 / 198136947425$

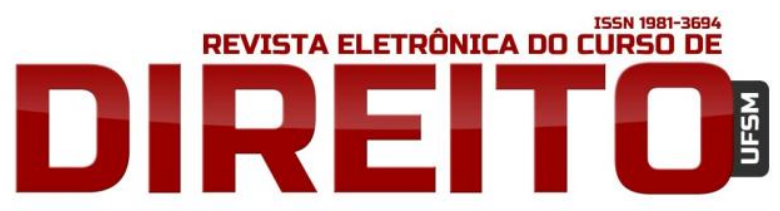

SOCIEDADE DE INFORMAÇÃO, AMBIENTE VIRTUAL E CÓDIGO DE DEFESA DO CONSUMIDOR: POSSIBILIDADE DE RESPONSABILIZAÇÃO DAS REDES SOCIAIS EM RAZÃO DE DANOS CAUSADOS AOS USUÁRIOS ATRAVÉS DA ÓTICA CONSUMERISTA

FERNANDO GABBI POLLI MAYUMI IGUCHI LUFT

busca sobre os mais variados assuntos: é, na verdade, a base "mecânica" da sociedade de informação.

\subsection{Redes sociais: fenômeno sem limites}

A rede social configura-se, atualmente, como uma estrutura social. Com ela tanto pessoas quanto organizações podem estar conectadas pelas mais diversas espécies de relações, valores e/ou objetivos. Como exemplos podemos citar Facebook, MySpace, Twitter (pessoais), Linkedin (profissional), dentre tantos outros.

Por ser um fenômeno social, o usuário, para aderir a determinado tipo de conexão, precisa compartilhar, identificar um objetivo, valor ou conhecimento. Para obter uma conta em uma rede social é preciso informar alguns dados pessoais. Literalmente, o usuário efetua um cadastro.

Não necessariamente as redes precisam ser pessoais ou profissionais, mas podem envolver objetivos religiosos, políticos, científicos, etc.

Os limites das redes não são limites de separação, mas limites de identidade. (...) Não é um limite físico, mas um limite de expectativas, de confiança e lealdade, o qual é permanentemente mantido e renegociado pela rede de comunicações ${ }^{5}$.

A rápida velocidade com que as informações se propagam, a grande quantidade de pessoas que conseguem atingir, a facilidade de acesso, a grande quantidade de informações pessoais que apresentam, a dificuldade de exclusão e controle sobre as informações divulgadas e o tempo em que as informações ficam disponíveis são algumas das características das redes sociais $^{6}$.

Tais características aliadas ao grau de confiança depositado pelos usuários fizeram com que a redes sociais virassem um fenômeno mundial da internet e, com isso, uma ferramenta de marketing e propaganda.

\footnotetext{
${ }^{5}$ CAPRA, Fritjof. Vivendo Redes. In: Duarte, Fábio; Quandt, Carlos; Souza, Queila. 0 Tempo Das Redes. Editora Perspectiva S/A, 2008. P. 21/23.

${ }^{6}$ BRASIL. Cartilha de segurança na internet. Fascículo Redes Sociais. Disponível em: <http://cartilha.cert.br/fasciculos/redes-sociais/fasciculo-redes-sociais.pdf> Acesso em: 27 nov. 2012.
} 
ISSN 1981-3694

(DOI) $10.5902 / 198136947425$

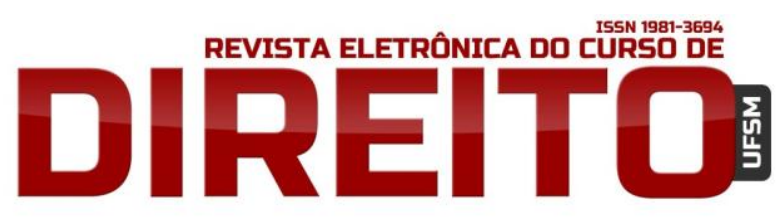

SOCIEDADE DE INFORMAÇÃO, AMBIENTE VIRTUAL E CÓDIGO DE DEFESA DO CONSUMIDOR: POSSIBILIDADE DE RESPONSABILIZAÇÃO DAS REDES SOCIAIS EM RAZÃO DE DANOS CAUSADOS AOS USUÁRIOS ATRAVÉS DA ÓTICA CONSUMERISTA

FERNANDO GABBI POLLI MAYUMI IGUCHI LUFT

\subsection{Informações de navegação e a barganha cibernética}

Atualmente na internet há duas espécies de informações relevantes que são levadas em conta quando ligadas a publicidades direcionadas: informações cadastrais e informações de preferências.

As primeiras - cadastrais - dizem respeito às informações solicitadas e necessárias para que seja finalizada a etapa cadastral do futuro usuário do sistema, ou do espaço do site, bem como aquelas não obrigatórias que são informadas no perfil do usuário.

Já as informações de preferências subdividem-se em "associativas" e “de navegação". As associativas são aquelas retiradas das preferências do usuário, ou seja, aquelas ligadas às características das páginas que este cadastra para receber atualizações ou ficar vinculado de alguma forma (conhecidas como "curtir" no Facebook ou "seguir" no Twitter).

Por sua vez, as de navegação são extraídas da forma mais engenhosa pelas prestadoras de serviço, visto que se utilizam dos dados inerentes da navegação do usuário, ou seja, para qual página aquele se dirige a partir do site de relacionamento. A conjugação de todos estes dados cria um perfil com grande riqueza de detalhes e características dos usuários, destinatário final das propagandas direcionadas e exploradas pelas redes sociais.

As informações obtidas são utilizadas como "moeda de troca" por parte do site de relacionamento. A rede social oferta a informação dos usuários para empresas, com interesse em divulgar seus serviços/produtos. A publicidade é direcionada e gerenciada pelo site com o uso das informações prestadas pelos consumidores, bem como aquelas inerentes de sua cotidiana navegação. Com isto estas empresas conseguem ofertar ao mercado de publicidade um serviço diferenciado e que aufere gigante lucro na internet.

As empresas exploradoras desta espécie de sítios eletrônicos, aparentemente gratuitos e de livre "locomoção do usuário", utilizam dados pessoais de navegação (site visitados regularmente e assuntos frequentes) como forma de destacar seus serviços (publicidade direcionada), auferindo lucro não apenas por veicularem propagandas aleatórias em site de relacionamento, mas por tentarem ofertar a determinado usuário os produtos e serviços que mais the interesse de acordo com as informações, sejam elas prestadas ou não, autorizadas ou não.

Ocorre que a conduta destas empresas e dos sites de relacionamento incorre em nítida violação da intimidade e privacidade do consumidor/usuário, protegidos expressamente pela 
ISSN 1981-3694

(DOI) $10.5902 / 198136947425$

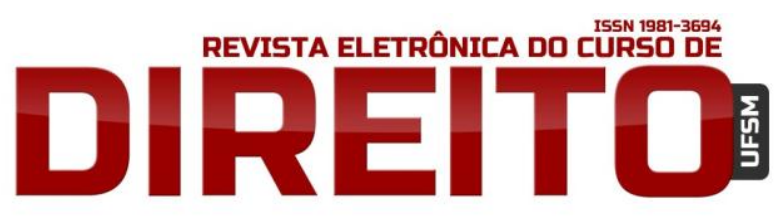

SOCIEDADE DE INFORMAÇÃO, AMBIENTE VIRTUAL E CÓDIGO DE DEFESA DO CONSUMIDOR: POSSIBILIDADE DE RESPONSABILIZAÇÃO DAS REDES SOCIAIS EM RAZÃO DE DANOS CAUSADOS AOS USUÁRIOS ATRAVÉS DA ÓTICA CONSUMERISTA

FERNANDO GABBI POLLI MAYUMI IGUCHI LUFT

Constituição Federal em seu art. 5, X: "são invioláveis a intimidade, a vida privada, a honra e a imagem das pessoas, assegurado o direito a indenização pelo dano material ou moral decorrente de sua violação ${ }^{7 "}$.

Leciona Alexandre de Moraes:

Desta forma, a defesa da privacidade deve proteger o homem contra: (a) a interferência em sua vida privada, familiar e doméstica; (b) a ingerência em sua integridade física ou mental, ou em sua liberdade intelectual e moral; (c) os ataques à sua honra e reputação; (d) sua colocação em perspectiva falsa; (e) a comunicação de fatos relevantes e embaraçosos relativos à sua intimidade; (f) o uso de seu nome, identidade ou retrato; (g) a espionagem e a espreita; (h) a intervenção na correspondência; (i) a má utilização de informações escritas e orais; (j) a transmissão de informes dados ou recebidos em razão de segredo profissional $^{8}$.

A violação decorre do uso de informações pessoais, bem como em colocação em perspectiva falsa - a primeira quebra da normalidade resulta da troca ocorrida entre os sites de relacionamento e as empresas patrocinadoras e a segunda, a partir do momento em que o usuário crê estar utilizando um serviço gratuito quando, na realidade, há contraprestação.

Em que pese a intimidade esteja ligada às relações subjetivas e de trato íntimo, percebese que há sim violação neste nível, a partir do momento em que a rede social sugere determinado tipo de produto/serviço considerando as pessoas interligadas pela rede social do usuário ("amigos" no Facebook, "seguidores" no Twitter).

A dinâmica comercial encontra-se tão bem engendrada que o usuário encontra-se vigiado cada vez que utiliza o serviço, aparentemente gratuito, sendo que cada movimento seu é coletado a fim de virar moeda de barganha em negociações publicitárias.

\section{PRIVACIDADE DISSIMULADA}

Atualmente, a internet não apenas permite que as pessoas entrem em contato umas com as outras, como também facilita o acesso à informação, cria novas formas de estudo, de trabalho, etc. Verifica-se que as invenções e o rápido avanço tecnológico estão modificando a compreensão do mundo; causando, dessa forma, uma necessária readaptação do modo de vida

7 BRASIL. Constituição Federal. Brasília: Senado Federal, 1988. Disponível em: < http://www.planalto.gov.br/ccivil_03/constituicao/constituicao.htm> Acesso em: 03 dez. 2012.

${ }^{8}$ MORAES, Alexandre de. Direito constitucional. 11. ed. São Paulo: Atlas, 2002. P.91. 
ISSN 1981-3694

(DOI) $10.5902 / 198136947425$

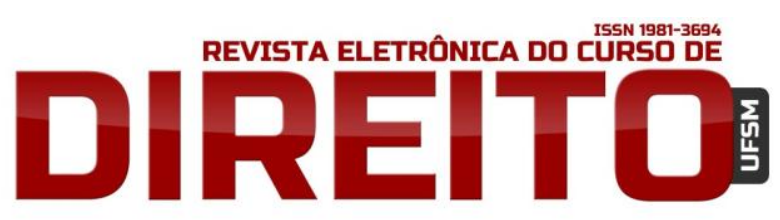

SOCIEDADE DE INFORMAÇÃO, AMBIENTE VIRTUAL E CÓDIGO DE DEFESA DO CONSUMIDOR: POSSIBILIDADE DE RESPONSABILIZAÇÃO DAS REDES SOCIAIS EM RAZÃO DE DANOS CAUSADOS AOS USUÁRIOS ATRAVÉS DA ÓTICA CONSUMERISTA

FERNANDO GABBI POLLI MAYUMI IGUCHI LUFT

do homem. Faz parte da vida cotidiana da grande maioria dos usuários da rede mundial de computadores a filiação e utilização de ambientes sociais cibernéticos 9 .

Por sua vez, a liberdade é a condição de ser livre, ou seja, a faculdade ou poder outorgado à pessoa para que possa agir segundo sua própria determinação ${ }^{10}$. Portanto, ao que parece, qualquer espécie de controle da liberdade de navegação na internet atenta à autodeterminação do usuário no que concerne ao livre deslocamento no ambiente virtual.

O problema da internet é ainda mais grave, uma vez que atende a interesses comerciais e baseia-se na utilização de informações colhidas dos próprios usuários (seja ela oriunda de dados prestados pelo cliente quando de cadastros necessários para acesso ao sistema ou do histórico de visitações e visualizações de páginas da internet). Neste sentido o usuário, também consumidor dos serviços prestados pelos sites que utiliza ${ }^{11}$, ao que parece, encontra-se sujeito a estas violações, as quais ocorrem constantemente no mundo cibernético.

No mesmo diapasão, na internet são encontradas publicidades direcionadas que se utilizam de mecanismos baseados em dados pessoais dos usuários da rede mundial de computadores, de modo a invadirem a sua intimidade desta forma ${ }^{12}$. Ainda,

o direito à privacidade sofre ameaças em decorrência do avanço tecnológico e da internet. Esta, por sua vez, se põe como um desafio à regulação pelo próprio sistema jurídico. A despeito das teorias que acreditavam ser a rede das redes ingovernável, a experiência nos demonstra que, estando em jogo direitos fundamentais e caros ao corpo social, é preciso que a internet seja regulada ${ }^{13}$.

É sabido que o direito à intimidade e à vida privada está positivado na Constituição da República Federativa do Brasil, contudo, esses direitos têm sofrido contínuo desrespeito à medida que cresce o desenvolvimento de novas tecnologias da informação, especialmente a

\footnotetext{
9 MALTINTI, Juliana de C. Tutela inibitória e internet: o processo civil aplicado na proteção da privacidade. XXX. Anais do XVII Congresso Nacional do CONPEDI, realizado em Brasília - DF nos dias 20, 21 e 22 de novembro de 2008. Disponível em: < http://www.epm.tjsp.jus.br/Sociedade/ArtigosView.aspx?ID=3090>. Acesso em: 27 dez. 2012.

${ }^{10}$ SILVA, De Plácido e. Vocabulário Jurídico. 24a Edição. Rio de Janeiro: Forense, 2004.

${ }^{11}$ FILOMENO, José Geraldo Brito. Manual de Direito do Consumidor. 10a edição. São Paulo: Atlas, 2010. P.23.

12 HOCH, Patrícia A. e SANTOS, Noemi de Freitas. Desafios À Proteção De Direitos Fundamentais Do Consumidor Na Sociedade Informacional: Uma Análise Da Nova Política De Privacidade Do Google E Do Anteprojeto de Lei Sobre Dados Pessoais. 2012. Disponível em: < http://nudiufsm. wordpress.com/artigos2/>. Acesso em: 22 dez. 2012.

${ }^{13}$ VIDAL, Gabriel R. Regulação do direito à privacidade na internet: o papel da arquitetura. Disponível em: <http://jus.com.br/revista/texto/17798/regulacao-do-direito-a-privacidade-na-internet-o-papelda-arquitetura\#ixzz2GHHKhPdD>. Acesso em: 23 dez. 2012.
} 
ISSN 1981-3694

(DOI) $10.5902 / 198136947425$

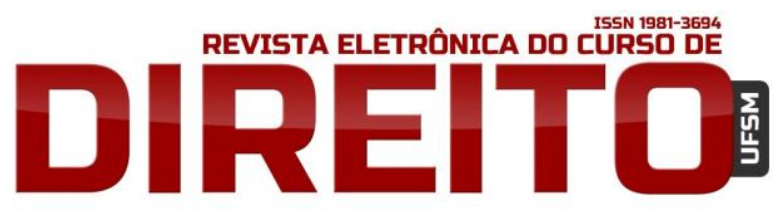

SOCIEDADE DE INFORMAÇÃO, AMBIENTE VIRTUAL E CÓDIGO DE DEFESA DO CONSUMIDOR: POSSIBILIDADE DE RESPONSABILIZAÇÃO DAS REDES SOCIAIS EM RAZÃO DE DANOS CAUSADOS AOS USUÁRIOS ATRAVÉS DA ÓTICA CONSUMERISTA

FERNANDO GABBI POLLI MAYUMI IGUCHI LUFT

Internet. Assim, nota-se que há uma possível afronta aos direitos fundamentais, uma vez que a utilização de dados pessoais pelas administradoras de sites de relacionamento afeta a intimidade dos indivíduos de forma indiscriminada ${ }^{14}$.

A dinâmica comercial encontra-se tão bem engendrada que o usuário vê-se vigiado cada vez que utiliza o serviço, aparentemente gratuito, sendo que cada movimento seu é coletado a fim de virar "moeda de barganha” em negociações publicitárias. Tais fatos levam a confecção de publicidades abusivas, uma vez que para tanto não há necessidade de que estas afetem financeiramente o consumidor, mas simplesmente em razão de atentarem a valores que sejam caros a sociedade de consumo ${ }^{15}$.

Esta prática também é realizada pelos navegadores - programas para acesso a internet , os quais, muitas das vezes, pertencem aos mesmos grupos econômicos dos administradores dos espaços cibernéticos (sites).

Neste sentido, Marcel Leonardi ${ }^{16}$, apoiando-se em Pereira (1980), Hughes (s.n.t.) e Kuhlen (2004), afirma:

[...] a privacidade significa o 'conjunto de informações a cerca do indivíduo que ele pode decidir sob seu exclusivo controle, ou comunicar, decidindo a quem, quando, onde e em que condições, sem a isso poder ser legalmente sujeito'. A privacidade é assim, 'o poder de revelar-se seletivamente ao mundo' e não significa apenas o direito de ser deixado em paz, mas também o direito de determinar quais tributos destes serão usados por outros.

Ou seja, é o indivíduo que tem o poder de decisão sobre as informações que the dizem respeito, não bastando, para configurar o respeito à privacidade, simplesmente não ser importunado.

Destarte, não se pode permitir que os administradores das redes sociais utilizem-se das informações pessoais de seus usuários de forma dissimulada, como ocorre atualmente.

Tampouco deve admitir-se que condicionem a fruição das redes mediante termos de publicidade de tais dados.

\footnotetext{
${ }^{14}$ ANDRADE, Allan D. M. M. de. 0 direito à intimidade e à vida privada em face das novas tecnologias da informação. Disponível em:

<http://www.faete.edu.br/revista/ODIREITOAINTIMIDADE_E_\%20A_VIDA_PRIVADA_EM_FACEDASNOVASTEC NOLOGIASDAINFORMACAO-Allan\%20Diego.pdf>. s. n. t. Acesso em: 24 dez. 2012.

${ }^{15}$ GRINOVER E OUTROS, Ada Pelegrini. Código Brasileiro de defesa do consumidor comentado pelos autores do anteprojeto. $9^{a}$ Edição. Rio de Janeiro: Forense, 2007.

${ }^{16}$ LEONARDI, Marcel. Tutela e Privacidade na Internet. $1^{\text {a }}$ Edição. São Paulo: Saraiva, 2012. P. 68.
} 


\title{
3 DO PROJETO DE LEI DO MARCO REGULATÓRIO DA INTERNET
}

Frente a esta realidade contemporânea de alargamento e universalização de acesso a rede mundial de computadores, mas do que urgente é a necessidade de criação de uma legislação que abarque as relações pessoais firmadas na internet, principalmente no que diz respeito a utilização de dados dos usuários. Nestes contexto o estado brasileiro, através do Ministério de Justiça, propos anteprojeto de lei, o qual tramita no Congresso Nacional, tendo por objetivo a proteção dos dados pessoais dos internautas.

Sobre o referido projeto de lei, tratam Patrícia Hoch e Noemi Santos:

\begin{abstract}
"O objetivo do anteprojeto de lei é assegurar o controle e a titularidade dos usuários sobre suas próprias informações pessoais, de modo a proteger o direito constitucional fundamental de privacidade, utilizando como fundamento o princípio da autodeterminação informativa, segundo o qual o internauta possui a prerrogativa de decidir sobre a utilização desses dados.

[...]

O anteprojeto de lei possui quarenta e oito artigos dispostos em quatro títulos. 0 primeiro trata da tutela dos dados pessoais em onze capítulos; o segundo aborda a tutela administrativa dos dados pessoais em outros dois capítulos; o terceiro título prevê a elaboração de códigos de boas práticas e, por fim, o quarto referese às disposições finais e transitórias ${ }^{17}$."
\end{abstract}

$\mathrm{Da}$ leitura do referido anteprojeto, verifica-se que este tras importantes regulamentações para o sistema, bem como legaliza conceitos da prática técnica da rede mundial de compoutadores. Ocorre que o mesmo texto peca no que diz respeito a responsabilização dos agentes provedores, visto a sua falta de abrangencia, deixando de lado questões específicas e importantes como a dos consumidores. O projeto de lei, "que apesar de já dispor de um anteprojeto de lei de proteção dos dados pessoais, esse ainda é incipiente e precisa ser aperfeiçoado, a fim de assegurar uma proteção mais ampla dos consumidores no

\footnotetext{
$17 \mathrm{HOCH}$, Patrícia A. e SANTOS, Noemi de Freitas. Desafios À Proteção De Direitos Fundamentais Do Consumidor Na Sociedade Informacional: Uma Análise Da Nova Política De Privacidade Do Google E Do Anteprojeto de Lei Sobre Dados Pessoais. 2012. Disponível em: < http://nudiufsm.wordpress.com/artigos2/>. Acesso em: 22 dez. 2012.
} 
ISSN 1981-3694

(DOI) $10.5902 / 198136947425$

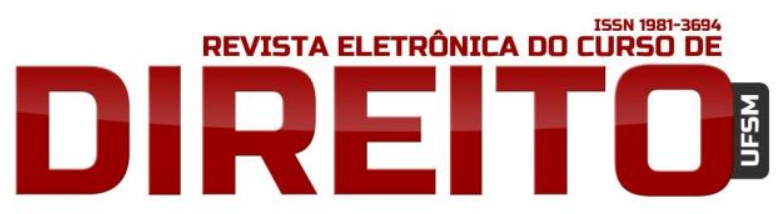

SOCIEDADE DE INFORMAÇÃO, AMBIENTE VIRTUAL E CÓDIGO DE DEFESA DO CONSUMIDOR: POSSIBILIDADE DE RESPONSABILIZAÇÃO DAS REDES SOCIAIS EM RAZÃO DE DANOS CAUSADOS AOS USUÁRIOS ATRAVÉS DA ÓTICA CONSUMERISTA

FERNANDO GABBI POLLI MAYUMI IGUCHI LUFT

ambiente virtual e de evitar, eficazmente, o uso de ferramentas, como por exemplo, cookies, spams, pop-ups e banners, de forma abusiva" ${ }^{18}$.

Deste modo, frente ao atual texto do projeto do Marco Regulatório Civil da Internet no Brasil, a relação existente entre os sites administradores de redes sociais e seus usuários devem ser comprendida como relação de consumo, frente as caracteristicas que passaram a ser expostas e enfrentadas.

\section{APLICABILIDADE DO CÓDIGO DE DEFESA DO CONSUMIDOR}

É sabido que a relação de consumo é regida pelo Código de Proteção e Defesa do Consumidor, Lei Federal 8.078/1990. Tal norma possui como pressuposto a existência de um desequilíbrio natural nas relações consumeristas. 0 Código trata o consumidor, destinatário final dos bens e serviços comercializados, como sendo a pessoa hipossuficiente, a qual precisa de atenção especial e auxílio na defesa de seus direitos.

Neste sentido importante é a lição de José Geraldo Brito Filomeno, que leciona o seguinte:

Entendemos que consumidor, abstraídas todas as conotações de ordem filosófica, tão-somente econômica, psicológica ou sociológica, e concentrando-nos basicamente na acepção jurídica, vem a ser qualquer pessoa física que, isolada ou coletivamente, contrate para consumo final, em benefício próprio ou de outrem, a aquisição ou locação de bens, bem como a prestação de serviços. Além disso, há que se equiparar a consumidor a coletividade que, potencialmente, esteja sujeita ou propensa à referida contratação. Caso contrário se deixaria à própria sorte, por exemplo, o público-alvo de campanhas publicitárias enganosas ou abusivas, ou então sujeito ao consumo de produtos ou serviços perigosos ou nocivos à sua saúde ou segurança ${ }^{19}$.

Do conceito acima, verifica-se que o consumidor é aquele que utiliza a rede social, pois se trata de uma prestação de serviços, ainda que aparentemente gratuita. Importa que a empresa fabricante, comerciante, ou prestadora de serviços é aquela que aufere lucro com o consumo direcionado, e, consequentemente, lucra mais com o seu aumento.

\footnotetext{
18 Idem.

${ }^{19}$ FILOMENO, José Geraldo Brito. Manual de Direito do Consumidor. 10 edição. São Paulo: Atlas, 2010. P.23.
} 
ISSN 1981-3694

(DOI) $10.5902 / 198136947425$

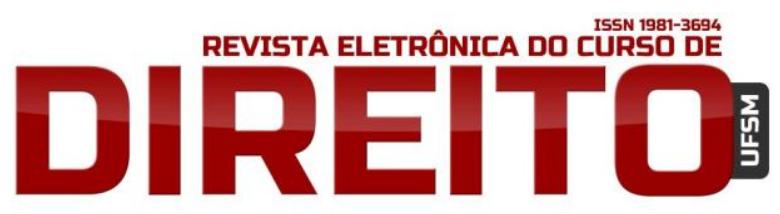

SOCIEDADE DE INFORMAÇÃO, AMBIENTE VIRTUAL E CÓDIGO DE DEFESA DO CONSUMIDOR: POSSIBILIDADE DE RESPONSABILIZAÇÃO DAS REDES SOCIAIS EM RAZÃO DE DANOS CAUSADOS AOS USUÁRIOS ATRAVÉS DA ÓTICA CONSUMERISTA

FERNANDO GABBI POLLI MAYUMI IGUCHI LUFT

Em primeira análise, verificamos que nos casos das redes sociais, aparentemente trata-se de serviços prestados de forma gratuita. Ledo engano. Se estudarmos mais a fundo a relação existente, verificaremos que os sites de relacionamento auferem incomensuráveis lucros em razão de utilização de seu espaço a fim de vincularem publicidades de seus patrocinadores.

Portanto é evidente que as redes sociais lucram com a oferta do produto/serviços de seus patrocinadores, pois seus usuários são consumidores em potencial daqueles serviços/produtos. Além do mais, mesmo pela ótica básica das relações de consumo, é evidente que o usuário das redes sociais apresenta-se como destinatário final de produtos prestados por aquele site de modo que, também por esta visão, fica caracterizada a relação legal que envolve o fornecer de serviço e o usuário.

Atente-se para o fato de que se necessita uma interpretação ampliativa, ou seja, a relação de consumo, nesta situação em específico, encontra-se "camuflada”, na medida em que não há relação direta entre consumidor e fornecedor. Todavia, não pode o usuário ser prejudicado e ficar sem proteção, pois uma análise mais apurada traz a relação de consumo à realidade.

Neste sentido, na doutrina de Lenio Luiz Streck:

[...] interpreta é descobrir o sentido e o alcance da norma, procurando a significação dos conceitos jurídicos. Para ela, interpretar é explicar; esclarecer; dar o verdadeiro significado do vocábulo; extrair, da norma, tudo o que nela se contém, revelando seu sentido apropriado para a vida real e conducente a uma decisão. É possível perceber nessa "busca do verdadeiro sentido da norma" e na "revelação" que deve ser feita pelo intérprete [...] "todo e qualquer aplicador do Direito (magistrado, autoridade pública, particular etc.) deve, sempre, descobrir o sentido da regra jurídica, apreender o seu significado e extensãon". (grifos no original)

Assim, não pode o aplicador do Direito deixar-se levar pela aparente gratuidade envolvendo a utilização das redes sociais. A contraprestação existe, todavia é realizada pela empresa patrocinadora que tem espaço para publicidade dentro da própria rede social.

Deste modo, verifica-se que estão presentes todos os requisitos necessários para a caracterização da relação existente entre os usuários de redes sociais e seus administradores como sendo uma relação tipicamente consumerista. Isto pelo fato de termos de um lado a

${ }^{20}$ STRECK, Lenio Luiz. Hermenêutica jurídica $e(m)$ crise: uma exploração hermenêutica da construção do Direito. 6. ed. Porto Alegre: Livraria do Advogado Editora, 2005. P. 98. 
ISSN 1981-3694

(DOI) $10.5902 / 198136947425$

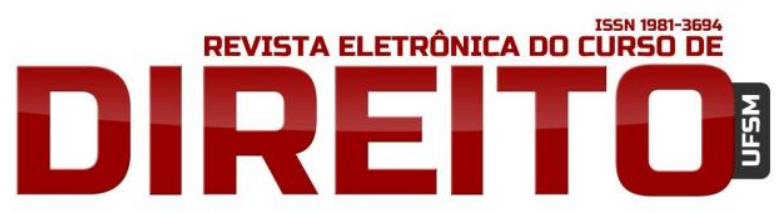

SOCIEDADE DE INFORMAÇÃO, AMBIENTE VIRTUAL E CÓDIGO DE DEFESA DO CONSUMIDOR: POSSIBILIDADE DE RESPONSABILIZAÇÃO DAS REDES SOCIAIS EM RAZÃO DE DANOS CAUSADOS AOS USUÁRIOS ATRAVÉS DA ÓTICA CONSUMERISTA

FERNANDO GABBI POLLI MAYUMI IGUCHI LUFT

empresa administradora do site, a qual oferta os serviços de espaço de comunicação, sendo que se outro lado esta o destinatário final do serviço ofertado, o qual é o usuário, portanto consumidor. Do mesmo modo, como já dito, a relação trás lucro ao administrador do site, pois este utiliza-se daquele "espaço virtual” para veicular propagandas de seus anunciantes.

O mesmo raciocínio é exposto por Hermano Marques da Silveira Junior, o qual afirma que:

\begin{abstract}
"No caso das Redes Sociais, tem-se a remuneração indireta. Como exemplo, coloca-se em análise a situação em que um empreendedor qualquer, deseja anunciar seu empreendimento aos usuários de uma determinada Rede Social, então, este paga ao fornecedor deste serviço para que se coloque uma certa publicidade, de tamanho e tipo pré-estabelecidos, no ambiente virtual da mesma. Ora, só existe o interesse do empreendedor de veicular sua propaganda no ambiente virtual da Rede Social, se este tiver acessos suficientes para suprir a sua necessidade mínima de visualizações por anúncio, ou mesmo se o público alvo deste empreendedor acessá-la. [...] Partindo das informações esclarecidas preliminarmente neste trabalho, considerar a Relação Jurídica entre o Fornecedor do Serviço Rede Social e o Usuário Consumidor deste Serviço, como sendo uma Relação de Consumo é simples consequiência da análise dos fatos jurídicos citados e da legislação que sobre eles incidem ${ }^{21}$."
\end{abstract}

Partindo desta premissa, nada mais correto que as empresas, principalmente as gigantes da internet, sejam responsabilizadas pela segurança de seus sites, bem como por todo o dano que este causar aos usuários, consumidores, principalmente no que tange à utilização de seus dados cadastrais.

É evidente que as relações formadas entre os usuários dos serviços de sites de relacionamentos (redes sociais) e as fornecedoras destes serviços são de suma importância, de modo que o tema apresenta-se pertinente e relevante do ponto de vista do direito dos consumidores.

\title{
5 POSSIBILIDADE DE RESPONSABILIZAÇÃO DAS REDES SOCIAIS POR USO INDEVIDO DE INFORMAÇÕES
}

Conforme demonstrado anteriormente, é evidente a relação de consumo existente entre os usuários de sites de relacionamentos e as empresas patrocinadoras das redes sociais. Estas

\footnotetext{
${ }^{21}$ JUNIOR, Hermano Marques da Silveira. A Legitimidade Passiva Dos Fornecedores Do Serviço Rede Social Nas Ações De Dano Moral Decorrentes Do Seu Ambiente Virtual. Disponível em: http://www. forumjuridico.org/topic/13672-a-legitimidade-passiva-dos-fornecedores-do-servico-redesocial-nas-acoes-de-dano-moral-decorrentes-do-seu-ambiente-virtual/. Acesso 20 de feveiro de 2013
} 
ISSN 1981-3694

(DOI) $10.5902 / 198136947425$

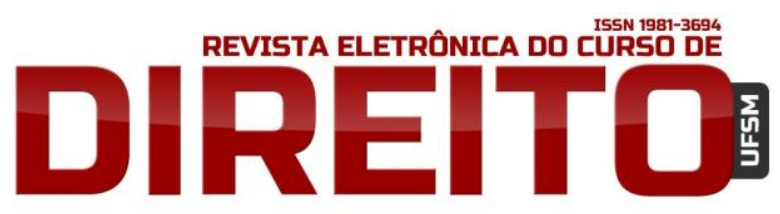

SOCIEDADE DE INFORMAÇÃO, AMBIENTE VIRTUAL E CÓDIGO DE DEFESA DO CONSUMIDOR: POSSIBILIDADE DE RESPONSABILIZAÇÃO DAS REDES SOCIAIS EM RAZÃO DE DANOS CAUSADOS AOS USUÁRIOS ATRAVÉS DA ÓTICA CONSUMERISTA

FERNANDO GABBI POLLI MAYUMI IGUCHI LUFT

devem zelar pelo bom uso de seus serviços, não possibilitando que o ambiente ofertado possa causas danos aos usuários.

Da mesma forma, deve haver zelo no que diz respeito à utilização dos dados prestados no momento do cadastro inicial e no seguir da utilização da rede de relacionamento. Com esta compreensão, podemos avançar no desenvolvimento da tese apresentada, passando a visualizar os sites de relacionamento como empresas integrantes de uma complexa cadeia de consumo.

Tal fato pode ser ilustrado pela Figura 01 que segue abaixo:

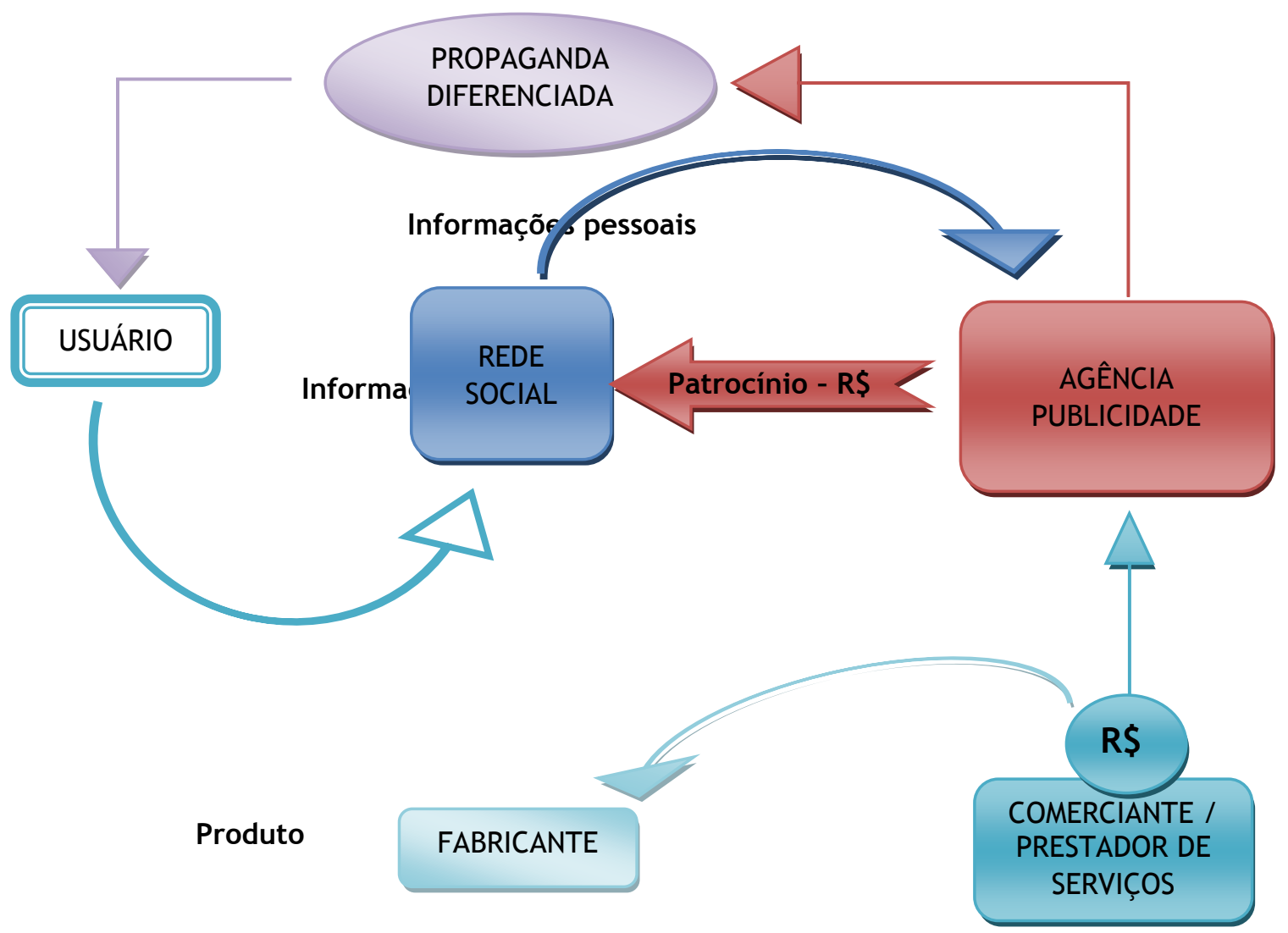

Figura 01: Organograma representativo das inter-relaçães existentes entre os agentes relacionados com os sites de redes sociais (confeccionado pelos autores deste estudo).

O Código de Proteção e Defesa do Consumidor, Lei Federal nº 8.078 de 1990, em seu artigo $3^{\circ}$ define fornecer como sendo a: 
ISSN 1981-3694

(DOI) $10.5902 / 198136947425$

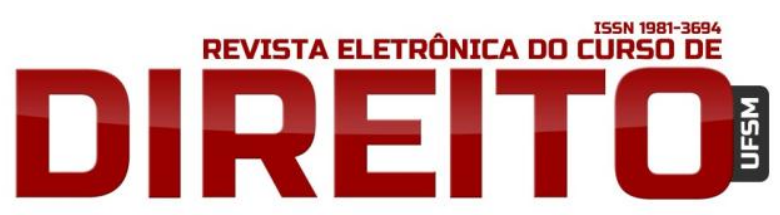

SOCIEDADE DE INFORMAÇÃO, AMBIENTE VIRTUAL E CÓDIGO DE DEFESA DO CONSUMIDOR: POSSIBILIDADE DE RESPONSABILIZAÇÃO DAS REDES SOCIAIS EM RAZÃO DE DANOS CAUSADOS AOS USUÁRIOS ATRAVÉS DA ÓTICA CONSUMERISTA

FERNANDO GABBI POLLI MAYUMI IGUCHI LUFT

[...] pessoa física ou jurídica, pública ou privada, nacional ou estrangeira, bem como os entes despersonalizados, que desenvolvem atividade de produção, montagem, criação, construção, transformação, importação, exportação, distribuição ou comercialização de produtos ou prestação de serviços ${ }^{22}$.

Portanto não há qualquer dúvida que os sites de relacionamento, os quais ofertam aos seus usuários a possibilidade de se inserirem em ambiente virtual para relacionar-se com demais usuários, é uma prestadora de serviços.

No mesmo sentido o referido artigo da legislação consumerista, em seu parágrafo segundo, segue referindo que "serviço" é compreendido como "qualquer atividade fornecida no mercado de consumo, mediante remuneração, inclusive as de natureza bancária, financeira, de crédito e securitária, salvo as decorrentes das relações de caráter trabalhista" ${ }^{23}$.

0 ponto que deve ser levando em consideração para a compreensão da responsabilização parte do modo como as normas consumeristas devem ser aplicadas ao caso concreto. Estas devem ser interpretadas do modo mais abrangente possível, vez que objetivam proteger a parte mais fraca das relações de consumo, de forma que a própria compreensão de consumidor deve ser alargada a fim de que contemple os usuários de sites de relacionamento (redes sociais).

Destarte, a compreensão de “remuneração" pelos serviços prestados, deve abranger também a que se dá de forma indireta, como no caso das redes sociais que se utilizam de informações pessoais para basear sua indústria de publicidade. As normas da Lei 8.078/90 devem ser interpretadas de modo que se retire de seu sistema, maior proteção ao consumidor, a fim de tentar trazer equilíbrio às relações de consumo, sejam elas remuneradas direta ou indiretamente.

Como referido nos itens anteriores, o fundamento para responsabilização dos sites de relacionamento é, principalmente, o fato de que os mesmos auferem lucro com as relações de consumo, pois, caso contrário, em não havendo dados pessoais de seus usuários, estes sites não receberiam a remuneração em tal monta como as que auferem atualmente. Do mesmo modo, se não houvesse público que fizesse uso do "espaço" virtual disponibilizado, nenhum anunciante teria interesse em veicular suas propagandas naquele ambiente.

\footnotetext{
${ }^{22}$ BRASIL, Lei Federal $n^{\circ} 8.078$ de 11 de setembro de 1990. Dispõe sobre a proteção do consumidor e dá outras providências. In: Diário Oficial da República Federativa do Brasil, Brasília, DF, 12 set.1990 (edição extra) e retificado em 10 jan. 2007.2 Disponível em: <http://www.planalto.gov.br/ccivil_03/Leis/L9974.htm> Acesso em: 03 set. 2012.

${ }^{23}$ Idem.
} 
ISSN 1981-3694

(DOI) $10.5902 / 198136947425$

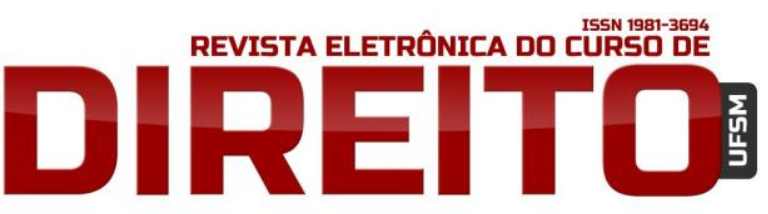

SOCIEDADE DE INFORMAÇÃO, AMBIENTE VIRTUAL E CÓDIGO DE DEFESA DO CONSUMIDOR: POSSIBILIDADE DE RESPONSABILIZAÇÃO DAS REDES SOCIAIS EM RAZÃO DE DANOS CAUSADOS AOS USUÁRIOS ATRAVÉS DA ÓTICA CONSUMERISTA

FERNANDO GABBI POLLI MAYUMI IGUCHI LUFT

\section{JURISPRUDÊNCIA PÁTRIA}

Relevante para a compreensão da solução proposta para a tutela dos consumidores é o estudo da atual posição dos tribunais que compõe o poder judiciário de nosso país.

Em pesquisa junto aos tribunais superiores verificou-se que a interpretação das normas do Código de Proteção e Defesa do Consumidor, se dá da forma mais alargada possível, a fim de que haja a configuração da relação de consumo.

Veja-se que a tese proposta encontra respaldo no Superior Tribunal de Justiça (STJ):

REsp 1316921 / RJ RECURSO ESPECIAL 2011/0307909-6.

CIVIL E CONSUMIDOR. INTERNET. RELACÃO DE CONSUMO. INCIDÊNCIA DO CDC. GRATUIDADE DO SERVIÇO. INDIFERENÇA. PROVEDOR DE PESQUISA. FILTRAGEM PRÉVIA DAS BUSCAS. DESNECESSIDADE. RESTRIÇÃO DOS RESULTADOS. NÃOCABIMENTO. CONTEÚDO PÚBLICO. DIREITO À INFORMAÇÃO.

1. A exploração comercial da Internet sujeita as relações de consumo daí advindas à Lei $\mathrm{n}^{\circ}$ 8.078/90.

2. O fato de o serviço prestado pelo provedor de serviço de Internet ser gratuito não desvirtua a relação de consumo, pois o termo "mediante remuneração", contido no art. $3^{\circ}$, $\S 2^{\circ}$, do CDC, deve ser interpretado de forma ampla, de modo a incluir o ganho indireto do fornecedor.

3. O provedor de pesquisa é uma espécie do gênero provedor de conteúdo, pois não inclui, hospeda, organiza ou de qualquer outra forma gerencia as páginas virtuais indicadas nos resultados disponibilizados, se limitando a indicar links onde podem ser encontrados os termos ou expressões de busca fornecidos pelo próprio usuário.

(...)

9. Recurso especial provido.

Trata-se de ação de reparação de danos por parte da Maria da Graça Xuxa Meneghel em face do site de pesquisas Google. O Superior Tribunal de Justiça entendeu pela configuração da relação do consumo visto que a remuneração se dava através do espaço disponibilizado pelo próprio portal para publicar propagandas de todas as espécies.

Para melhor compreensão, trecho do voto da Mins Nancy Adrighi:

Parece inegável que a exploração comercial da Internet sujeita as relações jurídicas de consumo daí advindas à Lei $n^{\circ} 8.078 / 90$. Newton De Lucca aponta o surgimento de "uma nova espécie de consumidor (...) - a do consumidor internauta - e, com ela, a necessidade de proteção normativa, já tão evidente no plano da economia tradicional" (Direito e Internet: aspectos jurídicos relevantes. Vol. II. São Paulo: Quartier Latin, 2008, p. 27).

Com efeito, as peculiaridades inerentes a essa relação virtual não afastam as bases caracterizadoras de um negócio jurídico clássico: (i) legítima manifestação 
ISSN 1981-3694

(DOI) $10.5902 / 198136947425$

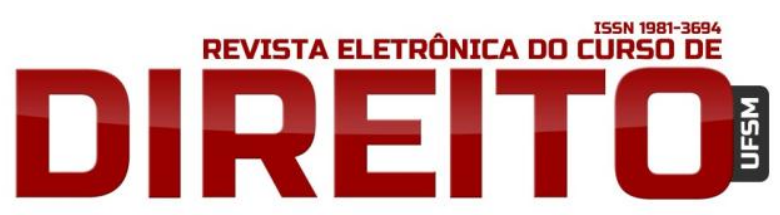

SOCIEDADE DE INFORMAÇÃO, AMBIENTE VIRTUAL E CÓDIGO DE DEFESA DO CONSUMIDOR: POSSIBILIDADE DE RESPONSABILIZAÇÃO DAS REDES SOCIAIS EM RAZÃO DE DANOS CAUSADOS AOS USUÁRIOS ATRAVÉS DA ÓTICA CONSUMERISTA

Fernando Gabbi Polli MAYUMI IGUCHI LUFT

de vontade das partes; (ii) objeto lícito, possível e determinado ou determinável; (iii) e forma prescrita ou não defesa em lei. Fernando Antônio de Vasconcelos observa que "o serviço preconizado na Lei 8.078/90 é o mesmo prestado pelas várias empresas que operam no setor [rede virtual]. Fica, pois, difícil dissociar o prestador [provedor] de serviços da Internet do fornecedor de serviços definido no Código de Defesa do Consumidor" (Internet. Responsabilidade do provedor pelos danos praticados. Curitiba: Juruá, 2004, p. 116).

Vale notar, por oportuno, que o fato de o serviço prestado pelo provedor ser gratuito não desvirtua a relação de consumo, pois o termo "mediante remuneração", contido no art. $3^{\circ}$, § $2^{\circ}$, do CDC, deve ser interpretado de forma ampla, de modo a incluir o ganho indireto do fornecedor.

$\mathrm{Na}$ lição de Cláudia Lima Marques, "a expressão 'remuneração' permite incluir todos aqueles contratos em que for possível identificar, no sinalagma escondido (contraprestação escondida), uma remuneração indireta do serviço" (Comentários ao código de defesa do consumidor: arts. $1^{\circ}$ ao 74 . São Paulo: RT, 2003, p. 94).

No caso da GOOGLE, é clara a existência do chamado cross marketing - ação promocional entre produtos ou serviços em que um deles, embora não rentável em si, proporciona ganhos decorrentes da venda de outros. Apesar das pesquisas realizadas via GOOGLE SEARCH serem gratuitas, a empresa vende espaços publicitários no site bem como preferências na ordem de listagem dos resultados das buscas.

Retomando os ensinamentos de Cláudia Lima Marques, a autora anota que "estas atividades dos fornecedores visam lucro, são parte de seu marketing e de seu preço total, pois são remunerados na manutenção do negócio principal”, concluindo que "no mercado de consumo, em quase todos os casos, há remuneração do fornecedor, direta ou indireta, como um exemplo do 'enriquecimento' dos fornecedores pelos serviços ditos 'gratuitos' pode comprovar" (op. cit., p. 95).

Há, portanto, inegável relação de consumo nos serviços de Internet, ainda que prestados gratuitamente ${ }^{24}$.

Do voto apresentado extrai-se que a gratuidade dos serviços prestados é aparente, na medida em que existe remuneração. No trecho acima transcrito, resta claro que não se discute acerca de ser o pagamento direto ou não, tendo em vista a amplitude da expressão "mediante remuneração".

De modo mais preciso, no que concerne às redes sociais, verifica-se que o STJ adota a mesma posição, inclinando-se pela aplicação do Código de Defesa do Consumidor na proteção dos usuários, mesmo que da primeira análise o serviço prestado apresente-se como gratuito.

Vejamos:

\footnotetext{
${ }^{24}$ BRASIL. Superior Tribunal de Justiça. Acórdão de decisão que deu provimento a recurso especial. Recurso Especial $n^{\circ}$ 1.316.921-RJ. Maria da Graça Xuxa Meneghel e Google Brasil Internet Ltda. Relatora: Ministro Nancy. 26 de junho de 2012. Disponível em:

<https://ww2.stj.jus.br/revistaeletronica/ita.asp?registro=201103079096\&dt_publicacao=29/06/2012>. Acesso em: 06 de dezembro 2012.
} 
ISSN 1981-3694

(DOI) $10.5902 / 198136947425$

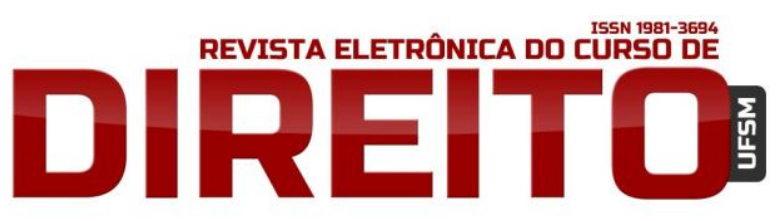

SOCIEDADE DE INFORMAÇÃO, AMBIENTE VIRTUAL E CÓDIGO DE DEFESA DO CONSUMIDOR: POSSIBILIDADE DE RESPONSABILIZAÇÃO DAS REDES SOCIAIS EM RAZÃO DE DANOS CAUSADOS AOS USUÁRIOS ATRAVÉS DA ÓTICA CONSUMERISTA

FERNANDO GABBI POLLI MAYUMI IGUCHI LUFT

REsp 1308830 / RS RECURSO ESPECIAL 2011/0257434-5

CIVIL E CONSUMIDOR. INTERNET. RELAÇ̃̃O DE CONSUMO. INCIDÊNCIA DO CDC. GRATUIDADE DO SERVICSO. INDIFERENCA. PROVEDOR DE CONTEÚDO. FISCALIZAÇÃO PRÉVIA DO TEOR DAS INFORMAÇÕES POSTADAS NO SITE PELOS USUÁRIOS. DESNECESSIDADE. MENSAGEM DE CONTEÚDO OFENSIVO. DANO MORAL. RISCO INERENTE AO NEGÓCIO. INEXISTÊNCIA. CIÊNCIA DA EXISTÊNCIA DE CONTEÚDO ILÍCITO. RETIRADA IMEDIATA DO AR. DEVER. DISPONIBILIZACÃO DE MEIOS PARA IDENTIFICAÇÃO DE CADA USUÁRIO. DEVER. REGISTRO DO NÚMERO DE IP. SUFICIÊNCIA.

1. A exploração comercial da internet sujeita as relações de consumo daí advindas à Lei $\mathrm{n}^{\circ}$ 8.078/90.

2. $O$ fato de o serviço prestado pelo provedor de serviço de internet ser gratuito não desvirtua a relação de consumo, pois o termo mediante remuneração, contido no art. $3^{\circ}$, $\S 2^{\circ}$, do CDC, deve ser interpretado de forma ampla, de modo a incluir o ganho indireto do fornecedor.

3. A fiscalização prévia, pelo provedor de conteúdo, do teor das informações postadas na web por cada usuário não é atividade intrínseca ao serviço prestado, de modo que não se pode reputar defeituoso, nos termos do art. 14 do CDC, o site que não examina e filtra os dados e imagens nele inseridos.

4. O dano moral decorrente de mensagens com conteúdo ofensivo inseridas no site pelo usuário não constitui risco inerente à atividade dos provedores de conteúdo, de modo que não se thes aplica a responsabilidade objetiva prevista no art. 927, parágrafo único, do $\mathrm{CC} / 02$.

5. Ao ser comunicado de que determinado texto ou imagem possui conteúdo ilícito, deve o provedor agir de forma enérgica, retirando o material do ar imediatamente, sob pena de responder solidariamente com o autor direto do dano, em virtude da omissão praticada.

6. Ao oferecer um serviço por meio do qual se possibilita que os usuários externem livremente sua opinião, deve o provedor de conteúdo ter o cuidado de propiciar meios para que se possa identificar cada um desses usuários, coibindo o anonimato e atribuindo a cada manifestação uma autoria certa e determinada. Sob a ótica da diligência média que se espera do provedor, deve este adotar as providências que, conforme as circunstâncias específicas de cada caso, estiverem ao seu alcance para a individualização dos usuários do site, sob pena de responsabilização subjetiva por culpa in omittendo.

7. A iniciativa do provedor de conteúdo de manter em site que hospeda rede social virtual um canal para denúncias é louvável e condiz com a postura esperada na prestação desse tipo de serviço - de manter meios que possibilitem a identificação de cada usuário (e

de eventuais abusos por ele praticado) - mas a mera disponibilização da ferramenta não é suficiente. É crucial que haja a efetiva adoção de providências tendentes a apurar e resolver as reclamações formuladas, mantendo o denunciante informado das medidas tomadas, sob pena de se criar apenas uma falsa sensação de segurança e controle.

8. Recurso especial não provido. ${ }^{25}$

${ }^{25}$ BRASIL. Superior Tribunal de Justiça. Acórdão de decisão que negou provimento a recurso especial. Recurso Especial n ${ }^{\circ}$ 1.308.830-RS. Eduardo Brezolin e Google Brasil Internet Ltda. Relatora: Ministro Nancy. 08 de maio de 2012. Disponível em: 
ISSN 1981-3694

(DOI) $10.5902 / 198136947425$

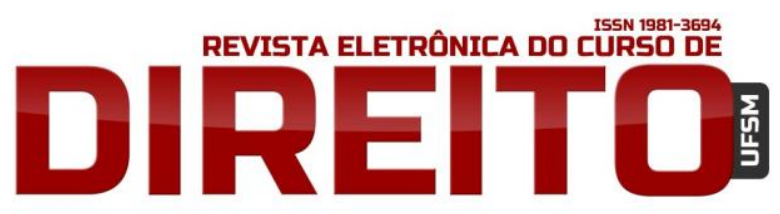

SOCIEDADE DE INFORMAÇÃO, AMBIENTE VIRTUAL E CÓDIGO DE DEFESA DO CONSUMIDOR: POSSIBILIDADE DE RESPONSABILIZAÇÃO DAS REDES SOCIAIS EM RAZÃO DE DANOS CAUSADOS AOS USUÁRIOS ATRAVÉS DA ÓTICA CONSUMERISTA

FERNANDO GABBI POLLI MAYUMI IGUCHI LUFT

A presente ação de indenização por dano moral tratava de ofensas veiculadas pelas redes sociais através de falso perfil de usuário. Ainda que se tenha uma relação entre dois usuários, os recentes posicionamentos do Tribunal Superior abrem precedentes no sentido de responsabilização civil da rede social, na medida em que admite a incidência do Código de Defesa do Consumidor neste tipo de relação, ou seja, entende pela existência da relação de consumo, independente da gratuidade do serviço.

A existência de um canal próprio para reclamações, bem como a adoção de medidas eficientes para coibir danos aos consumidores, deve ser observada a fim de que seja criado um ambiente virtual mais seguro para todos.

Em pesquisa junto ao Tribunal de Justiça do Estado do Rio Grande do Sul, verificou-se que muito embora não pacificada, alguns julgados apresentam-se seguindo a posição defendida neste estudo.

Ementa: APELACÃ̃ CÍVEL. RESPONSABILIDADE CIVIL. DANO MORAL. PESSOA JURÍDICA. ORKUT. PROVEDOR DE SERVIÇO. INCIDÊNCIA DO CÓDIGO DE DEFESA DO CONSUMIDOR. CRIAÇÃO DE PERFIL FALSO. DEVER DE INDENIZAR. APLICABILIDADE DO CDC. Existe relação de consumo entre o demandado e os usuários do Orkut, uma vez que o Google se enquadra no conceito de fornecedor de serviços, conforme estatui o art. $3^{\circ}$, $\S 2^{\circ}$, do CDC. A expressão mediante remuneração leva à compreensão de que devem ser incluídos todos os contratos nos quais é possível identificar uma remuneração indireta do serviço, o que ocorre na espécie; embora o serviço prestado pelo Google não seja pago diretamente pela usuária, ora autora, ainda assim há o ganho indireto do fornecedor, sendo inegável a incidência das regras da lei consumerista. DEVER DE INDENIZAR CONFIGURADO. Responsabilidade imputada ao servidor de hospedagem, diante da sua desídia, pois mesmo após ter sido notificado acerca da existência de suposto perfil falso criado em nome da autora, não retirou a página do site de relacionamento Orkut, fato que só veio a fazer em momento tardio, após o ajuizamento da demanda, por meio de ordem judicial. Acolhimento do pedido indenizatório por caracterizado o ato ilícito. DANOS EMERGENTES. Desacolhimento pela falta de comprovação dos prejuízos materiais havidos, ônus processual da autora (art. 333, I, CPC). APELAÇÃO PROVIDA. UNÂNIME. (Apelação Cível No 70044304038, Nona Câmara Cível, Tribunal de Justiça do RS, Relator: Tasso Caubi Soares Delabary, Julgado em 28/09/2011). ${ }^{26}$

<https://ww2.stj.jus.br/revistaeletronica/ita.asp?registro=201103079096\&dt_publicacao=29/06/2012>. Acesso em: 06 de dezembro 2012.

${ }^{26}$ BRASIL. Tribunal de Justiça do Rio Grande do Sul. Acórdão de decisão que deu provimento a apelação civel. Apelação $\mathrm{n}^{\circ}$ 70044304038. Bb brasil-artigos esportivos ltda e google brasil internet ltda. Relatoro: tasso caubi soares delabary. 08 de maio de 2012. Disponível em: < HTTP: / /WWW.TJRS.JUS.BR/BUSCA/?Q=GOOGLE+BRASIL+INTERNETT\&TB=JURISNOVA\&PESQ=EMENTARIO\&P ARTIALFIELDS=\%28TIPODECISAO\%3AAC\%25C3\%25B3RD\%25C3\%25A30\%7CTIPODECISAO\%3AMONOCR\%25C3\%25A 1TICA\%7CTIPODECISAO\%3ANULL\%29\&REQUIREDFIELDS=\&AS_Q=>. ACESSO EM: 06 DE DEZEMBRO 2012. 
ISSN 1981-3694

(DOI) $10.5902 / 198136947425$

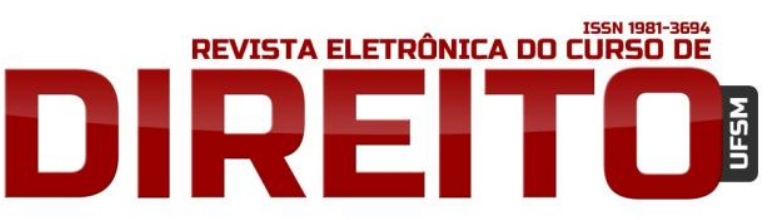

SOCIEDADE DE INFORMAÇÃO, AMBIENTE VIRTUAL E CÓDIGO DE DEFESA DO CONSUMIDOR: POSSIBILIDADE DE RESPONSABILIZAÇÃO DAS REDES SOCIAIS EM RAZÃO DE DANOS CAUSADOS AOS USUÁRIOS ATRAVÉS DA ÓTICA CONSUMERISTA

FERNANDO GABBI POLLI MAYUMI IGUCHI LUFT

Do acórdão acima extrai-se o voto do Des. Tasso Caubi Soares Delabary, o qual apresenta a tese de "remuneração indireta", onde o prestador de serviço (administrador do site de relacionamento pela internet) aufere lucro com a utilização de seu espaço pelos usuários, visto que o sítio é um veículo de propagandas aos seus usuários.

De início, cabe apreciar a incidência ou não das regras do Código de Defesa do Consumidor à espécie sub judice.

Quanto a essa questão, melhor refletindo sobre a matéria, revi meu posicionamento anterior, passando a entender que, em casos como o dos autos, é possível a incidência das regras do Código de Defesa do Consumidor.

Então, com a devida vênia ao posicionamento do juízo de primeiro grau, tenho que a presente ação está sujeita às regras do Código de Defesa do Consumidor; ocorre que existe relação de consumo entre o demandado e os usuários do Orkut, uma vez que o Google se enquadra no conceito de fornecedor de serviços, conforme estatui o art. $3^{\circ}$, § $2^{\circ}$, do CDC. A expressão mediante remuneração leva à compreensão de que devem ser incluídos todos os contratos nos quais é possível identificar uma remuneração indireta do serviço, como se vê na hipótese dos autos; e, embora o serviço prestado pelo Google não seja pago diretamente pelo usuário, ainda assim há o ganho indireto do fornecedor, o que torna presente a relação de consumo entre as partes. ${ }^{27}$

Do citado, tem-se, mais do que nunca demonstrado que, mesmo não sendo unânime a posição defendida, esta pode ser claramente utilizada para tutelar os usuários dos serviços dos sites de relacionamento, redes sociais, no caso de danos que estes possam vir a suportar em razão do uso do espaço cibernético oferecido.

\section{CONCLUSÃO}

A ideia de sociedade de informação apresentada neste trabalho demonstra o motivo pelo qual as redes sociais tornaram-se tão essenciais no cotidiano das pessoas: a capacidade de obter e compartilhar qualquer informação, instantaneamente, de qualquer lugar e da maneira mais adequada.

\footnotetext{
${ }^{27}$ BRASIL. TRIBUNAL DE JUSTICA DO RIO GRANDE DO SUL. ACÓRDÃO DE DECISÃO QUE DEU PROVIMENTO A APELAÇÃO CIVEL. APELAÇÃO N ${ }^{\circ}$ 70044304038. BB BRASIL-ARTIGOS ESPORTIVOS LTDA E GOOGLE BRASIL INTERNET LTDA. RELATORO: TASSO CAUBI SOARES DELABARY. 08 DE MAIO DE 2012. DISPONÍVEL EM: < http: / / www.tjrs. jus.br/busca/?q=google+brasil+internett\&tb=jurisnova\&pesq=ementario\& partialfields $=\% 2$ 8TipoDecisao\%3Aac\%25C3\%25B3rd\%25C3\%25A30\%7CTipoDecisao\%3Amonocr\%25C3\%25A1tica\%7CTipoDecisao \%3Anull\%29\&requiredfields=\&as_q=>. Acesso em: 06 de dezembro 2012.
} 
ISSN 1981-3694

(DOI) $10.5902 / 198136947425$

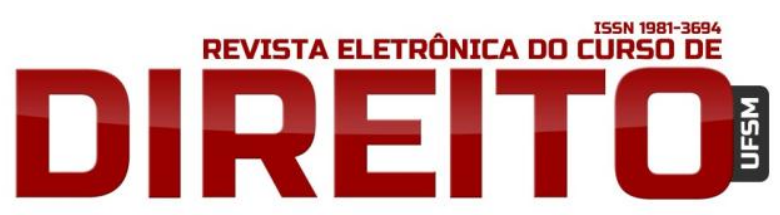

SOCIEDADE DE INFORMAÇÃO, AMBIENTE VIRTUAL E CÓDIGO DE DEFESA DO CONSUMIDOR: POSSIBILIDADE DE RESPONSABILIZAÇÃO DAS REDES SOCIAIS EM RAZÃO DE DANOS CAUSADOS AOS USUÁRIOS ATRAVÉS DA ÓTICA CONSUMERISTA

FERNANDO GABBI POLLI MAYUMI IGUCHI LUFT

Este compartilhamento instantâneo pode ser utilizado para todo e qualquer setor da sociedade: relações pessoais, profissionais, marketing e propaganda, e até mesmo para observar o princípio da publicidade no caso da Administração Pública. Em que pese a grande utilização das redes por parte da sociedade, verifica-se que não existe diploma específico que regule a relação existente entre o usuário e o site de relacionamento.

Todavia, necessário mencionar que a inexistência de tal diploma legal não inviabiliza a responsabilização por eventuais danos sofridos pelos usuários. A uma, porque a tutela da privacidade encontra proteção na Constituição Federal. A duas, porque, ainda que dissimulada, a relação existente é a de consumo, protegida pela Carta Magna e por lei específica.

Destarte, verifica-se possível e divida a aplicação o Código de Defesa do Consumidor aos danos eventualmente sofridos por aqueles que usufruem das mídias sociais, pois a responsabilidade decorre, como visto, do lucro auferido com a relação existente entre usuário, rede social e empresa patrocinadora. Não é possível permitir que o consumidor, usuário das redes sociais, parte mais frágil da relação entabulada, sofra com abusos inerentes a esta relação, como a utilização de dados pessoais.

Ao ensaiar uma resposta para a questão proposta neste artigo, observou-se que a doutrina nacional, bem como a jurisprudência, compreende que a ligação jurídica existente entre os sites de relacionamento na internet possuem características suficientes para serem entendidas como relações de consumo propriamente ditas, independente de a remuneração ser paga diretamente pelo usuário.

Portanto, frente a realidade existente, confrontada com a legislação pátria, verifica-se que deve, a relação existente entre o usuário das redes sociais e os administradores destas, ser tuteladas pela Lei Federal 8.078/90, de modo proteger o consumidor destes serviços quanto aos abusos listados.

Deste modo, no caso de ato ilícito sofrido pelo usuário, tem-se a possibilidade de responsabilização das redes de relacionamento utilizando-se o próprio Código de Defesa do Consumidor, sendo que tal entendimento, acertadamente, já está sendo aplicado no âmbito dos Tribunais.

\section{REFERÊNCIAS}

ANDRADE, Allan D. M. M. de. 0 direito à intimidade e à vida privada em face das novas tecnologias da informação. Disponível em: <http://www.faete.edu.br/revista/ODIREITOAINTIMIDADE_E_\%20A_VIDA_PRIVADA_EM_FACEDASN OVASTECNOLOGIASDAINFORMACAO-Allan\%20Diego.pdf>. s. n. t. Acesso em: 24 dez. 2012. 
ISSN 1981-3694

(DOI) $10.5902 / 198136947425$

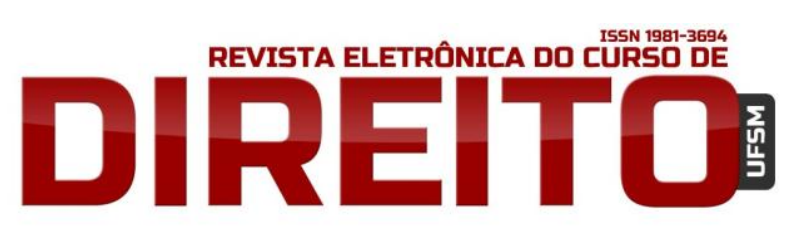

SOCIEDADE DE INFORMAÇÃO, AMBIENTE VIRTUAL E CÓDIGO DE DEFESA DO CONSUMIDOR: POSSIBILIDADE DE RESPONSABILIZAÇÃO DAS REDES SOCIAIS EM RAZÃO DE DANOS CAUSADOS AOS USUÁRIOS ATRAVÉS DA ÓTICA CONSUMERISTA

FERNANDO GABBI POLLI MAYUMI IGUCHI LUFT

BRASIL, A sociedade de informação no Brasil - Publicação realizada pelo Grupo Telefônica no Brasil; $1^{a}$ ed. - Dez. 2002.

- Artigo publicado no site TECHTUDO: História das redes sociais: do tímido Classmates até o boom do Facebook. < http://www.techtudo.com.br/artigos/noticia/2012/07/historiadas-redes-sociais.html> Acesso em 04 dez. 2012.

. Constituição Federal. Brasília: Senado Federal, 1988. Disponível em:

<http://www.planalto.gov.br/ccivil_03/constituicao/constituicao.htm> Acesso em: 27 nov. 2012.

. Cartilha de segurança na internet. Fascículo Redes Sociais. Disponível em: <http://cartilha.cert.br/fasciculos/redes-sociais/fasciculo-redes-sociais.pdf> Acesso em: 27 nov. 2012.

. Lei Federal $n^{\circ} 8.078$ de 11 de setembro de 1990. Dispõe sobre a proteção do consumidor e dá outras providências. In: Diário Oficial da República Federativa do Brasil, Brasília, DF, 12 set.1990 (edição extra) e retificado em 10 jan. 2007. Disponível em: <http://www.planalto.gov.br/ccivil_03/Leis/L9974.htm> Acesso em: 03 set. 2012.

. Superior Tribunal de Justiça. Acórdão de decisão que deu provimento a recurso especial. Recurso Especial no 1.316.921-RJ. Maria da Graça Xuxa Meneghel e Google Brasil Internet Ltda. Relatora: Ministro Nancy. 26 de junho de 2012. Disponível em: < https: / /ww2.stj.jus.br/revistaeletronica/ita. asp?registro=201102574345\&dt_publicacao=19/06/ 2012>. Acesso em: 06 de dezembro 2012>.

. Superior Tribunal de Justiça. Acórdão de decisão que negou provimento a recurso especial. Recurso Especial ${ }^{\circ}$ 1.308.830-RS. Eduardo Brezolin e Google Brasil Internet Ltda. Relatora: Ministro Nancy. 08 de maio de 2012. Disponível em:

<https: / /ww2.stj.jus.br/revistaeletronica/ita.asp?registro=201103079096\&dt_publicacao=29/06 /2012>. Acesso em: 06 de dezembro 2012.

- Tribunal de Justiça do Rio Grande do Sul. Acórdão de decisão que deu provimento a apelação civel. Apelação $\mathrm{n}^{\circ} 70044304038$. Bb brasil-artigos esportivos ltda e google brasil internet ltda. Relatoro: tasso caubi soares delabary. 08 de maio de 2012. Disponível em: < HTTP:/ /WWW.TJRS.JUS.BR/BUSCA/?Q=GOOGLE+BRASIL+INTERNETT\&TB=JURISNOVA\&PESQ=EME NTARIO\&PARTIALFIELDS=\%28TIPODECISAO\%3AAC\%25C3\%25B3RD\%25C3\%25A30\%7CTIPODECISAO\%3 AMONOCR\%25C3\%25A1TICA\%7CTIPODECISAO\%3ANULL\%29\&REQUIREDFIELDS=\&AS_Q=>. Acesso em: 06 dez. 2012.

CAPRA, Fritjof. Vivendo Redes. In: Duarte, Fábio; Quandt, Carlos; Souza, Queila. O Tempo Das Redes. Editora Perspectiva S/A, 2008. P. 21/23.

FILOMENO, José Geraldo Brito. Manual de Direito do Consumidor. $10^{a}$ edição. São Paulo: Atlas, 2010. P.23. 
ISSN 1981-3694

(DOI) $10.5902 / 198136947425$

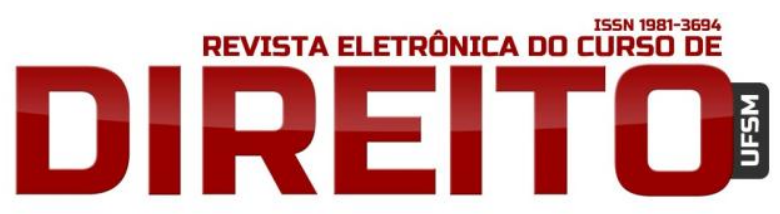

SOCIEDADE DE INFORMAÇÃO, AMBIENTE VIRTUAL E CÓDIGO DE DEFESA DO CONSUMIDOR: POSSIBILIDADE DE RESPONSABILIZAÇÃO DAS REDES SOCIAIS EM RAZÃO DE DANOS CAUSADOS AOS USUÁRIOS ATRAVÉS DA ÓTICA CONSUMERISTA

FERNANDO GABBI POLLI MAYUMI IGUCHI LUFT

FREIRE, Rodrigo da Cunha Lima. O processo civil na sociedade da informação: estudo de um caso. Revista do Instituto dos Advogados de São Paulo, n. 17, São Paulo: Revista dos Tribunais, 2006.

GRINOVER E OUTROS, Ada Pelegrini. Código Brasileiro de defesa do consumidor comentado pelos autores do anteprojeto. 9 ${ }^{\mathrm{a}}$ Edição. Rio de Janeiro: Forense, 2007.

HOCH, Patrícia A. e SANTOS, Noemi de Freitas. Desafios À Proteção De Direitos Fundamentais Do Consumidor Na Sociedade Informacional: Uma Análise Da Nova Política De Privacidade Do Google E Do Anteprojeto de Lei Sobre Dados Pessoais. 2012. Disponível em: < http://nudiufsm.wordpress.com/artigos-2/>. Acesso em: 22 dez. 2012.

JUNIOR, Hermano Marques da Silveira. A Legitimidade Passiva Dos Fornecedores Do Serviço Rede Social Nas Ações De Dano Moral Decorrentes Do Seu Ambiente Virtual. 2011. Disponível em: http: / /www.forumjuridico.org/topic/13672-a-legitimidade-passiva-dos-fornecedores-doservico-rede-social-nas-acoes-de-dano-moral-decorrentes-do-seu-ambiente-virtual/. Acesso em: 20 de fevereiro de 2013

KELSEN, Hans. Teoria Pura do Direito. 6ª Edição. São Paulo: Martins Fontes, 2000.

LEONARDI, Marcel. Tutela e Privacidade na Internet. $1^{\text {a }}$ Edição. São Paulo: Saraiva, 2012.

MALTINTI, Juliana de C. Tutela inibitória e internet: o processo civil aplicado na proteção da privacidade. XXX. Anais do XVII Congresso Nacional do CONPEDI, realizado em Brasília - DF nos dias 20, 21 e 22 de novembro de 2008. Disponível em: <

http://www.epm.tjsp.jus.br/Sociedade/ArtigosView.aspx?ID=3090>. Acesso em: 27 dez. 2012.

MORAES, Alexandre de. Direito constitucional. 11. ed. São Paulo: Atlas, 2002.

SILVA, De Plácido e. Vocabulário Jurídico. 24ª Edição. Rio de Janeiro: Forense, 2004.

STRECK, Lenio Luiz. Hermenêutica jurídica e $(m)$ crise: uma exploração hermenêutica da construção do Direito. 6. ed. Porto Alegre: Livraria do Advogado Editora, 2005.

VIDAL, Gabriel R. Regulação do direito à privacidade na internet: o papel da arquitetura. Disponível em: <http://jus.com.br/revista/texto/17798/regulacao-do-direito-a-privacidade-nainternet-o-papel-da-arquitetura\#ixzz2GHHKhPdD>. Acesso em: 23 dez. 2012.

Recebido em: 07.12.2012

Revisado em: 21.01.2013

Aprovado em: 26.02 .2013 